\title{
Hubungan Kualitas Tidur dan Masalah Mental Emosional pada Remaja Sekolah Menengah
}

\author{
Meita Dhamayanti, Faisal, Elma Citra Maghfirah \\ Departemen Ilmu Kesehatan Anak Fakultas Kedokteran Universitas Padjadjaran Rumah Sakit Dr. Hasan Sadikin, \\ Bandung \\ Latar belakang. Tidur berperan penting dalam menjaga kesehatan emosional. Masalah mental emosional berdampak negatif terhadap \\ remaja dan memicu perilaku berisiko tinggi. \\ Tujuan. Menganalisis hubungan kualitas tidur dengan mental emosional pada remaja. \\ Metode. Studi observasional analitik dengan rancangan potong lintang. Pemilihan sampel dilakukan secara simple random sampling. \\ Penelitian dilakukan di SMA di Jatinangor pada bulan April-Juli 2017. Pengambilan data dengan menggunakan kuesioner. Uji statistik \\ deskriptif digunakan untuk analisis data karakteristik subjek, uji koefisien korelasi Crammer's v untuk analisis korelasi kualitas tidur \\ dan mental emosional. \\ Hasil. Sebanyak 79 siswa berusia 15-17 tahun dari tiga SMA, 39 laki-laki dan 40 perempuan, rerata usia 16 tahun, 36 kualitas tidur \\ baik dan 43 buruk. Kualitas tidur dan masalah mental emosional menunjukkan korelasi signifikan $(\mathrm{p}<0,05)$ dengan kekuatan korelasi \\ sedang (Crammer's v=0,422).
}

Kesimpulan. Terdapat korelasi kualitas tidur dan masalah mental emosional pada remaja SMA di Jatinangor. Sari Pediatri 2019;20(5):283-8

Kata kunci: emosional, kualitas tidur, mental, remaja

\section{Correlation Sleep Quality and Mental Emotional Problems in High School Adolescents}

\author{
Meita Dhamayanti, Faisal, Elma Citra Maghfirah
}

Background. Sleep has an important role in maintaining emotional health. Mental emotional problems might lead a negative impact on adolescent development and triggered high-risk behavior.

Objective. To analyze the correlation between sleep quality and mental emotional in adolescents.

Methods. Observational analytic using cross-sectional design, with simple random sampling method. This study was conducted in high schools in Jatinangor from April-July 2017. Data were collected using questionnaire. The subject characteristics were analyzed by descriptive statistics, while sleep quality and mental emotional were analyzed by Crammer's v correlation coefficient test.

Result. A total of 79 subjects were students aged 15-17 years from three high schools, 39 male and 40 female, median aged were 16, sleep quality good and bad were 36 and 43, respectively. The sleep quality and mental emotional problem were significant moderate strength correlation $(\mathrm{p}<0.05)$; (Crammer's $v=0.422)$.

Conclusion. There was a correlation between sleep quality and mental emotional problems in high school adolescents at Jatinangor. Sari Pediatri 2019;20(5):283-8

Keywords: emotional, sleep quality, adolescent

Alamat korespondensi: Meita Dhamayanti. Departemen Ilmu Kesehatan Anak Fakultas Kedokteran UNPAD Rumah Sakit Dr. Hasan Sadikin Bandung, Jl. Pasteur no.38 Bandung, Indonesia 40163. Email: meita.dh@gmail.com 
Meita Dhamayanti: Hubungan kualitas tidur dan masalah mental emosional pada remaja sekolah menengah

M asa remaja merupakan tahap perkembangan transisi antara masa kanak-kanak dan dewasa. Perubahan perkembangan fisik, psikis, dan sosial yang tidak sesuai mengakibatkan masalah mental emosinal pada remaja. ${ }^{1}$ Masalah tersebut jika tidak ditindaklanjuti dengan baik dapat memberikan dampak negatif terhadap perkembangan remaja tersebut di kemudian hari. Gangguan pada proses pematangan karakter dapat memicu terjadinya gangguan mental emosional yang mengarah kepada perilaku berisiko tinggi. ${ }^{2}$ Berdasarkan Riset kesehatan dasar (Riskesdas) 2007, sebanyak $8,7 \%$ penduduk Indonesia kelompok usia 15-24 tahun mengalami gangguan mental emosional. ${ }^{3}$

Salah satu faktor yang turut berperan dalam perkembangan mental emosional pada remaja adalah pola tidur. Pola tidur terutama durasi dan kualitas tidur berperan penting dalam menjaga kesehatan emosional. ${ }^{4}$ Studi epidemiologi di Ethiopia menunjukkan 49\% remaja mengalami kualitas tidur yang buruk. ${ }^{5}$ Gangguan tidur, seperti kekurangan tidur, dapat merangsang kesulitan emosional yang dapat meningkatkan keadaan stres dan kecemasan secara subjektif, serta meningkatkan reaksi simpatetik terhadap stimulus yang tidak menyenangkan. ${ }^{4}$ Sementara itu, penelitian mengenai hubungan antara kualitas tidur dengan mental emosional khususnya pada remaja di Indonesia belum banyak ditemukan. Penelitian ini bertujuan untuk menganalisis korelasi antara kualitas tidur dan masalah mental emosional pada remaja.

\section{Metode}

Penelitian observasional analitik korelasional dengan rancangan potong lintang dilaksanakan di Jatinangor pada bulan April-Juli 2017. Pengukuran sampel berdasarkan rumus analitik korelatif dengan sampel minimal adalah 64 orang dan asumsi drop out sebesar 10\% menjadi 79 orang. Pemilihan sampel dilakukan dengan simple random sampling. Subjek pada penelitian ini adalah siswa-siswi SMA di Jatinangor yang berusia 15-17 tahun. Dari total lima SMA yang berada di Jatinangor, hanya tiga SMA yang bersedia terlibat dalam penelitian ini, yaitu SMAS Al-Masoem, SMAS Darul Fatwa, dan SMAS Plus Al-Falah. Pengambilan data dimulai pada bulan Mei hingga Juni 2017 setelah mendapat persetujuan etik dari Komite Etik Penelitian Kesehatan Fakultas Kedokteran Universitas Padjadjaran dengan nomor etik 502/UN6.C.10/PN/2017.

Kriteria inklusi pada penelitian ini adalah siswasiswi yang berusia 15-17 tahun dan bersedia menjadi responden. Kriteria eksklusi adalah siswa-siswi yang sedang sakit atau sedang dalam pengobatan, tidak datang ke sekolah, dan tidak mengisi kuesioner dengan lengkap.

Variabel penelitian ini adalah kualitas tidur dan masalah mental emosional. Masalah mental emosional ini terdiri dari kesulitan : (1) mental emosional keseluruhan (total kesulitan); (2) emosi, (3) perilaku, (4) hiperaktivitas, (4) hubungan antar teman sebaya dan (5) perilaku prososial. Data karakteristik terdiri dari jenis kelamin, usia, tinggal di rumah bersama orang tua atau tidak, jumlah saudara kandung, pesantren, dan kebiasaan selama 1 bulan terakhir yang terdiri dari konsumsi kafein, merokok, alkohol, olahraga, durasi penggunaan gawai dan media sosial, serta penggunaan gawai pada malam hari sebelum tidur.

Jenis data yang digunakan pada penelitian ini merupakan data primer dari pengisian kuesioner oleh subjek. Kuesioner yang digunakan adalah Strength Difficulities Questionare (SDQ) dan The Pittsburgh Sleep Quality Index (PSQI). Masalah mental emosional menggunakan kuesioner Strength Difficulities Questionare (SDQ) yang telah diterjemahkan ke dalam bahasa Indonesia dan telah divalidasi. ${ }^{6}$ Kuesioner ini digunakan untuk mengukur kesulitan dan kekuatan atau mental emosional remaja, terdiri dari 25 poin psikologis dan terbagi dalam 5 dimensi komponen, terdiri dari 4 dimensi kesulitan (masalah), yaitu emosional, perilaku, hiperaktivitas, hubungan antar teman sebaya dan 1 dimensi kekuatan yaitu perilaku prososial. Pada setiap pernyataan psikologis tersebut terdapat pilihan jawaban "tidak benar", "agak benar", dan "benar" yang dinilai dengan skor masing-masing nol, satu, atau dua. Total skor dari semua poin yang dijumlahkan kemudian akan menghasilkan tiga interpretasi, yaitu: normal, borderline dan abnormal.

Kualitas tidur diukur dengan kuesioner The Pittsburgh Sleep Quality Index (PSQI) terdiri dari 7 komponen, yaitu kualitas tidur subjektif (penilaian kualitas tidur menurut individu), latensi tidur (durasi ketika akan tidur hingga tertidur), durasi tidur, efisiensi tidur sehari-hari (rasio persentase antara jumlah total jam tidur dibagi dengan jumlah jam yang dihabiskan di tempat tidur), gangguan tidur, penggunaan obat 
tidur, dan disfungsi aktivitas di siang hari (mengantuk dan kurang antusias ketika beraktivitas di siang hari). Total skor dihitung dari masing-masing komponen dengan interpretasi yaitu kualitas tidur baik jika skor $<5$, dan buruk jika skor $>5$. Kuesioner PSQI ini telah mengalami uji reliabilitas dengan koefisien korelasi interclass $(\mathrm{r})=0,87$. Uji validitas PSQI yang dilakukan pada penelitian kualitas tidur di Indonesia pada 30 orang responden mendapatkan hasil nilai Cronbach alpha $0,766 .^{7}$

Karakteristik sosiodemografi dianalisis dengan statistik deskriptif dan disajikan dalam bentuk frekuensi dan persentase. Korelasi variabel kualitas tidur dan mental emosional dianalisis dengan uji koefisien korelasi Crammer's $v$ dengan nilai $\mathrm{p}<0,05$ dianggap signifikan secara statistik. Analisis statistik digunakan aplikasi SPSS versi 20.

\section{Hasil}

Karakterisitik dari 79 subjek yang telah mengisi kuesioner dengan lengkap dan memenuhi kriteria inklusi dan eksklusi tertera pada Tabel 1 . Rata-rata usia subjek adalah 16 tahun dengan rentang 15-17 tahun. Sebanyak $74,7 \%$ tinggal serumah dengan kedua orang tua. Kebiasaan subjek dalam 1 bulan terakhir, mempunyai riwayat konsumsi kafein $1-2 \mathrm{x} /$ minggu $(55,7 \%)$, olahraga $1 \mathrm{x} /$ minggu $(60,8 \%)$, menggunakan gawai dan media sosial $\geq 3$ jam/hari $(64,6 \%)$ dan sebelum tidur (79,7\%). Sementara itu, riwayat mengonsumsi alkohol dan merokok dalam 1 bulan terakhir masing-masing 2,5\% dan 31,6\%.

Berdasarkan analisis bivariabel data karakteristik subjek tidak menunjukkan perbedaan signifikan terhadap masalah mental emosional kecuali jumlah saudara kandung dan penggunaan gawai/media sosial $(\mathrm{p}<0,05)$.

Berdasarkan data kuesioner kualitas tidur, 36 subjek dengan kualitas baik dan 43 subjek kualitas buruk. Hasil korelasi kualitas tidur dengan mental emosional berdasarkan komponen SDQ, seperti tertera pada Tabel 2. Masalah mental emosional secara keseluruhan (total kesulitan SDQ) mempunyai korelasi signifikan dengan kualitas tidur $(\mathrm{p}<0,05)$, dan koefisien Crammer's v 0,422 menunjukkan kekuatan korelasi sedang. Komponen SDQ lainnya, yaitu emosi dan perilaku masing-masing berkorelasi signifikan dengan kualitas tidur dengan kekuatan korelasi yang lemah $(\mathrm{p}<0,05$; koefisien Crammer's v 0,289). Sementara itu komponen kesulitan hiperaktifitas dan hubungan teman sebaya, serta perilaku prososial tidak menunjukkan korelasi yang signifikan.

\section{Pembahasan}

Keluarga merupakan lingkungan yang berpengaruh bagi perkembangan anak. Orang tua bertanggung jawab pada penanaman nilai dan norma serta pembentukan perilaku anak. ${ }^{8}$ Pada penelitian ini, sebagian besar remaja tinggal bersama kedua orang tuanya. Hal ini serupa dengan penelitian prevalensi gangguan tidur dan depresi di Cina, 89\% siswa tinggal bersama kedua orang tuanya. ${ }^{9}$ Remaja yang tidak tinggal bersama orang tuanya atau kehilangan orang tua cenderung mengalami depresi. ${ }^{10}$

Jumlah saudara kandung dapat berkaitan dengan penghasilan dalam keluarga dan juga memengaruhi pola asuh serta hubungan antar saudara dalam keluarga yang dapat memengaruhi mental emosional. ${ }^{11}$ Jumlah saudara kandung pada penelitian ini memiliki perbedaan bermakna terhadap masalah mental emosional.

Sebuah studi di Amerika melaporkan bahwa remaja adalah pengguna kafein yang tinggi, dengan 83,2\% remaja mengonsumsi kafein secara rutin sedikitnya satu kali per hari. ${ }^{12}$ Pada penelitian ini sebagian besar remaja mengonsumsi kafein satu sampai dua kali per minggu. Penelitian di Swiss elaporkan bahwa kafein dapat mengurangi kualitas tidur orang dewasa maupun remaja. ${ }^{13}$

Sebuah penelitian melaporkan bahwa remaja yang merupakan pengguna berat media sosial cenderung depresi dan mempunyai banyak masalah, seringkali sedih atau tidak bahagia, dan sering bosan. $\underline{14}^{4}$ Remaja pada penelitian ini mempunyai kebiasaan menggunakan gawai dan media sosial $\geq 3$ jam/hari, serta menggunakan gawai sebelum tidur. Penggunaan gawai dan media sosial menjadi fenomena teknologi yang menyebabkan remaja kekurangan tidur serta memengaruhi kualitas tidur. $\frac{15}{}$

Pada penelitian ini didapatkan korelasi bermakna antara kualitas tidur dengan masalah emosional, masalah perilaku, dan total kesulitan pada remaja. Hal ini sesuai dengan studi korelasi yang mengatakan bahwa kualitas tidur yang buruk dapat memengaruhi kemampuan seseorang dalam meregulasi emosinya. ${ }^{16}$ 
Tabel 1. Ditribusi karakteristik responden

\begin{tabular}{|c|c|}
\hline Variabel & $\mathrm{n}(\%)$ \\
\hline \multicolumn{2}{|l|}{ Jenis kelamin } \\
\hline Laki-laki & $39(49,4)$ \\
\hline Perempuan & $40(50,6)$ \\
\hline Umur, median (minimal-maksimal) tahun & $16(15-17)$ \\
\hline \multicolumn{2}{|l|}{ Tinggal serumah dengan } \\
\hline Ayah \& ibu & $59(74,7)$ \\
\hline Hanya ayah/ibu & $6(7,6)$ \\
\hline Lain-lain & $14(17,7)$ \\
\hline \multicolumn{2}{|l|}{ Jumlah saudara kandung* (anak) } \\
\hline$<3$ & $40(50,6)$ \\
\hline$\geq 3$ & $39(49,4)$ \\
\hline \multicolumn{2}{|l|}{ Pesantren } \\
\hline Ya & $12(15,2)$ \\
\hline Tidak & $67(84,8)$ \\
\hline \multicolumn{2}{|l|}{ Kafein $(\mathrm{x} /$ minggu $)$} \\
\hline Tidak pernah & $16(20,3)$ \\
\hline $1-2$ & $44(55,7)$ \\
\hline $3-5$ & $13(16,5)$ \\
\hline Setiap hari & $6(7,6)$ \\
\hline \multicolumn{2}{|l|}{ Merokok } \\
\hline Ya & $25(31,6)$ \\
\hline Tidak & $54(68,4)$ \\
\hline \multicolumn{2}{|l|}{ Alkohol } \\
\hline Ya & $2(2,5)$ \\
\hline Tidak & $77(97,5)$ \\
\hline \multicolumn{2}{|l|}{ Olahraga (x/minggu) } \\
\hline Tidak pernah & $4(5,1)$ \\
\hline 1 & $48(60,8)$ \\
\hline $2-3$ & $21(26,6)$ \\
\hline$>3$ & $6(7,6)$ \\
\hline \multicolumn{2}{|l|}{ Penggunaan gawai \& media sosial* (jam/hari) } \\
\hline$<3$ & $28(35,4)$ \\
\hline$\geq 3$ & $51(64,6)$ \\
\hline \multicolumn{2}{|l|}{ Menggunakan gawai sebelum tidur } \\
\hline Ya & $63(79,7)$ \\
\hline Tidak & $16(20,3)$ \\
\hline
\end{tabular}

Sementara itu, antara kualitas tidur dengan masalah hiperaktivitas, hubungan antar sebaya, dan prososial, tidak terdapat korelasi yang bermakna. Berbeda dari penelitian ini, penelitian lain melaporkan bahwa kualitas tidur yang buruk berhubungan dengan gangguan hiperaktivitas atau attention-deficit/ hyperactivity disorder (ADHD). ${ }^{17}$ Kualitas tidur secara tidak langsung juga dapat berpengaruh terhadap hubungan antar teman sebaya dan prososial, sebagai hasil dari pengaruh kualitas tidur yang buruk yang menyebabkan masalah perilaku, seperti mudah marah, sulit, dan perilaku lainnya dapat memengaruhi sikap perilaku terhadap teman dan lingkungan sekitarnya. ${ }^{18}$

Berbagai faktor dari komponen kualitas tidur dapat memengaruhi mental dan emosional pada remaja. Kualitas tidur dapat dinilai dari beberapa aspek, seperti 
Meita Dhamayanti: Hubungan kualitas tidur dan masalah mental emosional pada remaja sekolah menengah

Tabel 2. Korelasi kualitas tidur dan mental emotional

\begin{tabular}{|c|c|c|c|c|c|c|}
\hline \multirow[t]{2}{*}{ Komponen SDQ } & & \multicolumn{2}{|c|}{ Kualitas tidur } & \multirow{2}{*}{$\begin{array}{l}\text { Total } \\
\mathrm{N}(\%)\end{array}$} & \multirow[t]{2}{*}{ Nilai P } & \multirow[t]{2}{*}{ Crammer's V } \\
\hline & & $\begin{array}{l}\text { Baik } \\
\text { n (\%) }\end{array}$ & $\begin{array}{l}\text { Buruk } \\
\mathrm{n}(\%)\end{array}$ & & & \\
\hline \multirow{3}{*}{$\begin{array}{l}\text { Total kesulitan } \\
\text { (masalah mental } \\
\text { emosional) }\end{array}$} & Normal & $28(77,8)$ & $17(39,5)$ & $45(57,0)$ & \multirow[t]{3}{*}{0,001} & \multirow[t]{3}{*}{0,422} \\
\hline & Borderline & $6(16,7)$ & $10(23,3)$ & $16(20,3)$ & & \\
\hline & Abnormal & $2(5,6)$ & $16(37,2)$ & $18(22,8)$ & & \\
\hline \multirow{4}{*}{$\begin{array}{l}\text { Dimensi kesulitan } \\
\text { emosional }\end{array}$} & & & & & \multirow{4}{*}{0,037} & \multirow{4}{*}{0,289} \\
\hline & Normal & $27(75,0)$ & $20(46,5)$ & $47(59,5)$ & & \\
\hline & Borderline & $3(8,3)$ & $7(16,3)$ & $10(12,7)$ & & \\
\hline & Abnormal & $6(16,7)$ & $16(37,2)$ & $22(27,8)$ & & \\
\hline \multirow[t]{3}{*}{ Perilaku } & Normal & $28(77,8)$ & $22(51,2)$ & $50(63,3)$ & \multirow[t]{3}{*}{0,037} & \multirow[t]{3}{*}{0,289} \\
\hline & Borderline & $6(16,7)$ & $12(27,9)$ & $18(22,8)$ & & \\
\hline & Abnormal & $2(5,6)$ & $9(20,9)$ & $11(13,9)$ & & \\
\hline \multirow[t]{3}{*}{ Hiperaktivitas } & Normal & $33(91,7)$ & $31(72,1)$ & $64(81,0)$ & \multirow[t]{3}{*}{0,087} & \multirow[t]{3}{*}{0,249} \\
\hline & Borderline & $2(5,6)$ & $8(18,6)$ & $10(12,7)$ & & \\
\hline & Abnormal & $1(2,8)$ & $4(9,3)$ & $5(6,3)$ & & \\
\hline \multirow{3}{*}{$\begin{array}{l}\text { Hubungan dengan } \\
\text { teman sebaya }\end{array}$} & Normal & $30(83,3)$ & $29(67,4)$ & $59(74,7)$ & \multirow[t]{3}{*}{0,236} & \multirow[t]{3}{*}{0,191} \\
\hline & Borderline & $5(13,9)$ & $10(23,3)$ & $15(19,0)$ & & \\
\hline & Abnormal & $1(2,8)$ & $4(9,3)$ & $5(6,3)$ & & \\
\hline \multicolumn{7}{|l|}{ Kekuatan } \\
\hline \multirow[t]{3}{*}{ Prososial } & Normal & $34(94,4)$ & $41(95,3)$ & $75(94,9)$ & \multirow[t]{3}{*}{0,502} & \multirow[t]{3}{*}{0,132} \\
\hline & Borderline & $2(5,6)$ & $1(2,3)$ & $3(3,8)$ & & \\
\hline & Abnormal & $0(0,0)$ & $1(2,3)$ & $1(1,3)$ & & \\
\hline Total & & $36(100,0)$ & $43(100,0)$ & $79(100,0)$ & & \\
\hline
\end{tabular}

latensi tidur, durasi tidur, kualitas tidur subjektif, efisiensi tidur sehari-hari, gangguan tidur, penggunaan obat tidur dan disfungsi di siang hari. Gangguan tidur dan kekurangan tidur dapat merangsang kesulitan emosional yang dapat meningkatkan keadaan stres dan kecemasan secara subjektif serta meningkatkan reaksi simpatetik terhadap stimulus yang tidak menyenangkan. Sebaliknya, tidur yang cukup secara konsisten berkaitan dengan peningkatan kesehatan emosional, yang secara spesifik berkaitan dengan jumlah durasi dan fisiologis rapid eye movement (REM) dalam tidur. ${ }^{4}$

Remaja dengan beberapa masalah tidur (seperti kesulitan tidur, menahan kantuk, atau terbangun lebih awal) dapat mengalami masalah kecemasan atau depresif. Durasi tidur yang pendek pada malam hari juga berhubungan dengan berkurangnya mood dan meningkatnya kecemasan pada dewasa muda. ${ }^{19}$ Selain itu, sebuah penelitian juga melaporkan bahwa masalah gangguan tidur dan kesehatan mental merupakan hubungan yang saling berkaitan dua arah. ${ }^{20}$
Keterbatasan pada penelitian ini, di antaranya adalah dapat berpotensi terjadinya recall bias dan variabel perancu yang tidak dianalisis lebih lanjut sehingga dapat memengaruhi hasil penelitian. Penelitian ini juga merupakan observasional korelatif dengan rancangan potong lintang yang hanya mencari korelasi sehingga tidak mampu menjelaskan hubungan sebab akibat antara kualitas tidur dan masalah mental emosional. Penelitian lebih lanjut perlu dilakukan dengan metode selain kuesioner dan ditambahkan dengan in depth interview, demikian pula dengan rancangan case control dapat menganalisis sebab akibat.

\section{Kesimpulan}

Kualitas tidur mempunyai korelasi bermakna dengan masalah mental emosional pada remaja di SMA di Jatinangor. 
Meita Dhamayanti: Hubungan kualitas tidur dan masalah mental emosional pada remaja sekolah menengah

\section{Daftar pustaka}

1. Davis SK, Humphrey N. Emotional intelligence predicts adolescent mental health beyond personality and cognitive ability. Pers Indiv Differ 2012;52:144-9.

2. IDAI Satgas Remaja. Masalah mental emosional pada remaja dalam bunga rampai kesehatan remaja. Jakarta: Badan Penerbit Ikatan Dokter Anak Indonesia; 2010.h.62-75.

3. Kementerian Kesehatan R. Laporan hasil riset kesehatan dasar (Riskesdas) Indonesia tahun 2007. Jakarta: Badan Penelitian dan Pengembangan Kesehatan Departemen Kesehatan RI; 2008.h.119-21.

4. Simon EB, Oren N, Sharon H, Kirschner A, Goldway N, Okon-Singer $\mathrm{H}$, dkk. Losing neutrality: the neural basis of impaired emotional control without sleep. J Neurosci 2015;35:13194-205.

5. Lemma S, Patel SV, Tarekegn YA, Tadesse MG, Berhane Y, Gelaye B, dkk. The epidemiology of sleep quality, sleep patterns, consumption of caffeinated beverages, and khat use among Ethiopian college students. Sleep Disord 2012;2012:1-11.

6. Wiguna T, Manengkei PSK, Pamela C, Rheza AM, Hapsari WA. Masalah emosi dan perilaku pada anak dan remaja di poliklinik jiwa anak dan remaja RSUPN dr. Ciptomangunkusumo (RSCM), Jakarta. Sari Pediatri 2016;12:270-7.

7. Antara A, Adnyana IMO, Samatra DPGP. Korelasi kualitas tidur dengan nyeri kepala primer pada siswa-siswi Sekolah Menengah Atas Negeri 1 Amlapura Kabupaten Karangasem. Medicina 2015;46:156-61.

8. Septiana N, Syahrul H. Faktor keluarga yang memengaruhi perilaku merokok pada siswa sekolah menengah pertama. Jurnal Ilmu Keperawatan 2016;4:1-14.

9. Guo L, Deng J, He Y, Deng X, Huang J, Huang G, dkk. Prevalence and correlates of sleep disturbance and depressive symptoms among Chinese adolescents: a cross-sectional survey study. BMJ open 2014;4:e005517.

10. Rusmil K, Effendi SH. Risiko masalah perkembangan dan mental emosional anak yang diasuh di panti asuhan dibandingkan dengan diasuh orangtua kandung. Majalah Kedokteran Bandung 2014;46:118-24.

11. Vandivere S, Yrausquin A, Allen T, Malm K, McKlindon A. Children in nonparental care: A review of the literature and analysis of data gaps. Children 2012;12:1.

12. Mitchell DC, Knight CA, Hockenberry J, Teplansky R, Hartman TJ. Beverage caffeine intakes in the US. Food Chem Toxicol 2014;63:136-42.

13. Aepli A, Kurth S, Tesler N, Jenni OG, Huber R. Caffeine consuming children and adolescents show altered sleep behavior and deep sleep. Brain Sci 2015;5:441-55.

14. Carroll J, Kirkpatrick R. Impact of social media on adolescent behavioral health. Oakland, CA: California Adolescent Health Collaborative; 2011.h.1-6.

15. Hysing M, Pallesen S, Stormark KM, Jakobsen R, Lundervold AJ, Sivertsen B. Sleep and use of electronic devices in adolescence: results from a large population-based study. BMJ open 2015;5:e006748.

16. Mauss IB, Troy AS, LeBourgeois MK. Poorer sleep quality is associated with lower emotion-regulation ability in a laboratory paradigm. Cogn Emot 2013;27:567-76.

17. Yoon SYR, Jain UR, Shapiro CM. Sleep and daytime function in adults with attention-deficit/hyperactivity disorder: subtype differences. Sleep Med 2013;14:648-55.

18. Stores G. Sleep problems in children and adolescents: Oxford: OUP Oxford; 2009.h.17-8.

19. Milojevich HM, Lukowski AF. Sleep and mental health in undergraduate students with generally healthy sleep habits. PloS one 2016;11:e0156372.

20. Bartlett D, Jackson M. The bidirectional nature of sleep problems and psychopathology. Med Today 2016;17:23-8. 